\title{
Still unconvinced on the use of salvage prostatectomy
}

\author{
Laurence H. Klotz, MD, FRCSC
}

Department of Urology, Sunnybrook Health Sciences Centre, Toronto, ON

See related article on page 87 .

Cite as: Can Urol Assoc J 2013;7:93. http://dx.doi.org/10.5489/cuaj.572

I am a skeptic when it comes to salvage prostatectomy. I have performed a number of these cases early in my career and concluded that the risk-benefit ratio was too high for my liking. I then decided to focus my efforts in what I thought were more rewarding areas. Do the results reported by Corocoran and colleagues ${ }^{1}$ change this opinion?

This study is a retrospective review of 21 cases of salvage prostatectomy post-external beam irradiation performed at a single tertiary referral centre over a 15 -year period. The results were reasonable: 12 patients remained bNED (biochemical non-evidence of disease), 3 died of prostate cancer, 6 had a bladder neck contracture, and 1 developed a recto-prostatic fistula. Continence data was only available on 13 of the 21 patients; $85 \%$ of these were reported to use one pad or less per day. The continence data were obtained retrospectively and were reported by the physician, hence the data may understate the actual rate of incontinence.

The striking point about this data is that the 21 patients represent about $0.5 \%$ of the 4500 or so patients treated with radiation at their centre during this period, and about $1.5 \%$ of the expected 1500 radiation failures. (The authors quote $0.01 \%$, but it isn't clear how this figure was derived). No information is provided about patient selection of this small group. One presumes that, as with prostate cancer treatment in general, provider preference played a major role.

How do their results compare to those treated more conservatively among the radiation failures? The group represented a cross-section of typical radiation patients. Despite the fact that these patients were selected from a much larger group of radiation failure patients, at the time of failure $38 \%$ were Gleason 6 and $43 \%$ Gleason 7 . Only $19 \%$ were Gleason 8 or higher. Of the 21 patients, $3(14 \%)$ died of prostate cancer with a median follow-up of about 6 years.

In the 2012 PR7 study of intermittent versus continuous androgen deprivation therapy (ADT) for radiation failure, ${ }^{2}$ the prostate cancer mortality at 7 years was virtually identi- cal; $15 \%$ in the continuous arm, and $18 \%$ in the intermittent arm.

It is therefore unclear whether the patients had an improved prostate cancer survival compared to a group of radiation failure patients treated with $A D T$. While ADT carries significant side effects, it does not cause bladder neck contractures, incontinence, or rectal-urethral fistulas. These can be life-altering consequences of salvage surgery. Further, the morbidity of ADT can be minimized by delaying the introduction of therapy, using an intermittent approach, and managing the anticipated side effects aggressively.

Finally, other options for local therapy exist which may have less morbidity. Minimally invasive ablation using thermal energy or cryoablation is appealing compared to surgical resection. My expectation is that the increasing use of magnetic resonance imaging joined to focal ablation for patients with a targetable lesion will become more widely accepted in the salvage setting. ${ }^{3}$ Focal salvage therapy in selected patients at least fulfills the mandate of primum non nocere, and may reduce the requirement for ADT.

The Vancouver group has achieved commendable results given the inherent risks and limitations of salvage prostatectomy. However, I remain unconvinced that this approach is worth the risks for patients.

Competing interests: None declared.

\section{References}

1. Corcoran NM, Godoy G, Studd RC, et al. Salvage prostatectomy post-definitive radiation therapy: The Vancouver experience. Can Urol Assoc J 2013;7:87-92. http://dx.doi.org/10.5489/cuaj.1 1056. Epub 24 Jan 2012.

2. Crook JM, $O^{\prime}$ Callaghan CJ, Duncan $G$, et al. Intermittent androgen suppression for rising PSA level after radiotherapy. N Engl J Med 2012;367:895-903. http://dx.doi.org/10.1056/NEJMoal201546

3. Ahmed HU, Cathcart P, McCartan N, et al. Focal salvage therapy for localized prostate cancer recurrence after external beam radiotherapy: a pilot study. Cancer 2012;1 18:4148-55. http://dx.doi. org/10.1002/cncr.27394

Correspondence: Dr. Laurence Klotz, Sunnybrook Health Sciences Centre, 2075 Bayview Ave., Room MG 204, Toronto, 0N M4N 3M5; fax: 416-480-6121; laurence.klotz@sunnybrook.ca 